\title{
The impact of the development of information technology tools of communication on digital culture and Internet slang
}

\author{
Yulia Andreevna Petrova, and Olga Nikolaevna Vasichkina \\ Rostov State University of Economics (RSEU), Rostov-on-Don, Russia
}

\begin{abstract}
A digital culture is such a vast and complex concept that is often difficult to define. However, using just a definition does not answer the question: what are digital culture and Internet slang? To gain a deeper understanding of a digital culture, you need to understand what makes a digital culture as it is. It is becoming increasingly clear that this area can be successfully explored only through the joint efforts of humanitarian, social, cultural and technical scientists, and therefore the integration and structuring of existing disciplinary approaches and results are necessary. Our research does not consider digital culture in terms of professional subculture, understanding of modern information technologies, their functioning, and professional language. In our research, the digital culture is considered in the range of the Internet user's personality. The topicality of the research is that digital culture and Internet slang are «interdisciplinary categories, with the help of which it is possible to analyze problems of cultural identity», mutual influence of culture and slang in the system of unified computer networks.
\end{abstract}

\section{Introduction}

In digital space, not only people come together, but also cultures and subcultures. They learn about each other and learn from each other, which ultimately leads to changes in lifestyle, culture and language. And even despite the language barrier and the values of dominant cultures, they experience not a negative, but a positive impact in the process of interacting with other members. The Internet has created a new generation with complex skills and knowledge in the field of information technology, where values are expressed, which support their transmission through experience and cultural awareness in digital space, as well as special knowledge, skills and social preferences. The purpose of this article is to define the cognitive attributes of the human digital environment, and to conceptualize the Internet environment in terms of levels of culture, society, personality for satisfying such functional needs as accommodation, achievement of aim and integration. The topicality of the research is that digital culture and Internet slang are «interdisciplinary categories, with the help of which it is possible to analyze problems of cultural identity», mutual influence of culture and slang in the system of unified computer networks, etc. 


\section{Methods}

A better understanding of the problem of digital culture, Internet slang helped to synthesize approaches from different disciplines. The conceptual analysis of the combined assumptions and perspectives into a single functional unit allowed solving the problem more detailed. The complexity of the synergistic strategy in the research has been measured by a dynamic indicator, namely, the potential for cultural and linguistic self-development, both in society and individuals, under the influence of the Internet, the speed of identity transmission through information and communication technologies in the global $21 \mathrm{st}$ century.

\section{Results}

We have seen how the speed and the spared of digital technology and the digitization have led to the emergence of a digital culture of Internet service users, which has potentially embraced all aspects of everyday life and provided a new field for research and analysis of cultural forms. Research on human connectivity and digital technology has already led to the emergence of such disciplines as digital linguistics, digital culture philosophy, digital ethnography, digital anthropology, technological anthropology, virtual anthropology, cyborg anthropology, Internet studies, information studies, eHistory, eHumanities, eScience [1] etc. There is a new understanding of the digital world through language, social relations and practices. New research in digital culture is leading to a new digital language.

\section{Discussion}

One of the characteristics of humanity, from existence to the present day, is the love of technology. Studies of the Internet, culture and language present different perspectives on the role of technology in society. One of which is technological determinism. This theoretical-methodological installation in philosophical and sociological concepts and studies considers «technology as an independent force that moves social changes», characterized by changes in cultural symbols, rules and norms of behaviour, social organizations or value systems that occur in both tangible and intangible cultural elements under the influence of the Internet [2].

It should be noted that in our present people cannot imagine life without information and computer technologies. On the street they talk and negotiate over the smartphones, virtual visit, book, pay for places, where they're going, including travel to other continents during their vacation... these are small actions that have already entered the tracked life. People use the latest technological devices smartphones, in fact, which are a computer that is nearby 24 hours a day. Communication is becoming more and more technologically mediated (e.g. radio, telephone, television, Internet, ICT). For most people, their morning begins with messages, checking profiles, watching news etc. Clicking, finger-pointing, touching your chosen application are poetic actions that the average user makes more than 2.617 times a day on average. For the heaviest users according to Dscout Research, the top $10 \%$ - average interactions doubled to 5,427 touches a day [3]. These figures are big, because the Internet can provide a large amount of different stuff, such as: send/post emails/messages, play online video games, buy over the Internet, share digital photos, blogging, banking, stock transactions, different social networking services [4].

In digital space, not only people become united, but also cultures and subcultures. They learn about each other and learn from each other, which ultimately leads to changes in lifestyle, culture and language. And even despite the language barrier and the values of 
dominant cultures, they experience not a negative, but a positive impact in the process of interacting with other members [5].

The Internet has created a new generation with complex information technology skills and knowledge, expressing values that support learning based on experience and cultural awareness in digital space, and having special knowledge, skills and social preferences. The notion of a network generation is consistent with the deterministic view of the impact of technology on society.

If you look at the origins of "digital communication» [6] - the invention of the computer, creation of the first connection between hosts in Arpanet (early packet network), the predecessor of the Internet, or the Internet revolution of the 1990s and development of Web 2.0, which led to the expansion of offline life through the use of virtual space. We will see the birth of a new culture that is inseparable from the birth of a new language. And since electronic communication was developed and used by a specific subculture of computer professionals, the creators of the first networks implementing the TCP / IP protocol set - Advanced Research Projects Agency Network, Language norms are impregnated with a specific set of words of this culture, which have led to the interchangeable use of the language of the conference rooms and football fields. With no doubt, a deep study of data available and accessible in social media. By the 21 st century, the online language had spread to the point where it was used by almost everyone on the planet, not just by computer professionals [6].

To date, there is certainly research in which scientists have addressed digital culture through complex methodologies. For example, the research of philosophical and sociological consequences «in the future of artificial intelligence» represented in academic work «Cyborg Manefest». Technology Science and Socialist Feminism at the end of the twentieth century (1984) by D. Haraway, in which the cyborg represents a succinct format of imaginary and material reality, the two joint centers structure any possibility of transformation [7], the process of identity formation of E. S. Pavlenko «Maturation as a process of identity formation: the possibilities of narrative analysis» (2016) [8].

Culture includes both behavioral and symbolic systems. The ability to transmit information across generations and between peers is a fundamental feature of the human species. The theoretical aspect of research of «digital media generation» [9] its culture and slang as «emotive dominant» [10] (the practice of their transformation is not genetically and/or epigenetically inherited characteristics of the human population. Due to the variability and development of culture, the methods of sending, coding and decoding change accordingly, «slang» can be perceived as an «essential element of culture [11]. In the process of inculcation, socialization and internalization, communication represents a «... linear one-way process in which the sender intentionally transmits the message to the recipient» [12]. The Wifi access point, a wireless router, facilitates the study of other cultures. To learn about the culture, its values, language, ideology and preferences, one can simply use a search tool and quickly access information about a particular culture, by questionnaire and statistical data [13].

The emergence of new ways of thinking and communicating using the Internet has become our new reality. Different words can create different contextual meanings, because «language forms thoughts», the nature of communicative choices, and the evaluative results of these choices. Smartphones are now the dominant form of interpersonal communication, and their use varies considerably between generations. The Internet is generally used by generations to view news, send and receive e-mail, exchange instant messages, play, listen to music, record, view videos, photo shoots, etc. Young representatives of the $\mathrm{Z}$ generation and the Alpha generation use the Internet for the most part for «flirting, jokes, information exchange and simply hanging out» [14]. Older people limit the use of their devices to fewer features. One of the used functions beyond the age range is photography. Although all 
generations tend to click on the photo icon on their gadgets, the use of this feature differs in the type of photograph taken, for instance, teenagers mostly take selfies [15].

While language is the most «explicit of the types of communication known to us» [16], with its linguistic features, both logical and social [17]. It should be noted that for many people who use smartphones and personal devices to transmit texts and visual messages, gestures in visual form have become a part of a digital culture language. So text editors use emoticons for graphic representations of facial expressions and hand or finger gestures, such as thumbs up, image of hands, which applauds for expressing agreement, excitement, like-mindedness, etc. Another development that reinforces the communicative use of gestures in the digital age is, for example, swiping fingers to letters for writing a word that is wanted on a smartphone. Consumers of Internet culture can also create their own gestures and symbolic signatures using creative keyboard symbols such as colons, dashes and parentheses [18].

Changes in culture are directly proportional to changes in language and vice versa, but this change is slow. Everything happens much faster online. The language changes almost every day, as proverbs, images and videos spread very rapidly from person to person. Accessing the Internet every day, or several times a day, you can see new memes being shared or new utterances being read that have never existed before, you can see the continued life of old phrases in a new context. F. Hartmann argues that «...a computerized network culture is considered to be a hope of communication based on increased importance that goes beyond culture and language, beyond the exclusive dominance of typographic writing. Created by computer technology and reinforced by telematic applications, the new knowledge design revolutionizes the language culture, typically replacing exclusive linear coding of speech and writing» [19].

Language is becoming more and more like the technology of thought and communication, and cultural norms are becoming the technology of social organization. In each case, the technology is a product of a particular historical period and is integrated into the social life of the people of that period.

\section{Conclusion}

Digital culture is similar to Internet slang - relatively new phenomenon that has not yet been widely spread in research. However, as this is gradually becoming the norm for global outreach to the audience around the world, both professional and academic interests in this field is growing exponentially, and is already characterized as a challenge to the scientific world because of techno-human synthesis, which is taking place in more aspects of all generations than ever before.

The evolution of digital cultural and linguistic development can be defined as the result of a multiplication operation in which culture and language are multipliers and information communication technologies are co-multipliers. The consequence of this work is evolution, in most part, is the evolution of the younger generation, the representatives of the young people become similar to cyborgs, «multifrenies», or fragmented versions of «I». They always exist in tandem with technology. In general, it can be said that the Internet is a cognitive revolution that has created a new Internet culture and a new Internet slang that has no age or geographical boundaries.

\section{References}

1. G. Mozhaeva, P. Mozhaeva Renha, SHS Web of Conferences, 26, 3, (2016) 
2. R. Jon McGee, R. L. Warms, Anthropological theory: an introductory history, Rowman \& Littlefield Publishers, 6, 56 (2016)

3. M. Winnick, R. Zolna, Mobile touches: A study on humans and their tech (2016) https://blog.dscout.com/

4. A. De Rycker, N. Yang Lai Fong, R. Ponnan, L. V. Sankar, L. C. Ean, SHS Web Conf., 33, 5, (2017)

5. E. Nesmeyanov, Yu. Petrova, R. Bachieva, O. Vasichkina, SHS Web Conf., 72 (2019)

6. S. Kiesler, J. Siegel, T. W. McGuire, American Psychologist, 39, 1123, (1984)

7. D. J. Haraway, Cyborg manifesto science, technology and socialist-feminism in the late twentieth century, Berkeley Socialist Review, essay, 292 (1985)

8. E. S. Pavlenko, RUDN Journal of Sociology, 16(2), 258 (2016)

9. M. M. Nazarov, V. N. Ivanov, E. A. Kublitskaya, RUDN Journal of Sociology, 20(3), 565 (2020)

10. A. S. Uwellenskaya, NGU Newsletter: Linguistics and Intercultural Communication, 18(1), 132 (2020)

11. S. Sheshukova, S. Lapitskaja, E. Proudchenko, SHS Web Conf., 69, 1 (2019)

12. R. Ellis, M. Klintock, If you take my meaning: theory into practice in human communication, 2, 187 (1994)

13. S. E. Boslaugh, Innovation, Encyclopedia Britannica (2016) https://www.britannica.com

14. D. Boyd, Cambridge, MA: The MIT Press (2008) https://www.ssrn.com/

15. C. Doherty, J. Kiley, A. Tyson, B. Jameson, The whys and hows of generations research (2015) https://www.pewresearch.org

16. Yu. A. Petrova, S. M. Karpoyan, Humanities and socio-economic sciences of the FSU, 3(94), 51 (2017)

17. J. Jonathan, Linguistic and Philosophical Investigations, 16, 49 (2017)

18. Y.A. Petrova, Language as a model of the value space of the culture, 92 (2019)

19. F. Hartmann, Speaking signs, web-publishing and the Viennese method of visual education (1997) https://www.heise.de/ 